\title{
Lateral Size Effect on Electrochemical Capacitor Performance of Reduced Graphite Oxide Nanosheets
}

\section{Zhongwei LEI, ${ }^{\text {a }}$ Toshio SAKAI, ${ }^{\mathbf{b}}$ and Wataru SUGIMOTOa,*}

a Faculty of Textile Science and Technology, Shinshu University, 3-15-1 Tokida, Ueda, Nagano 386-8567, Japan

b Faculty of Engineering, Shinshu University, 4-17-1 Wakasato, Nagano, Nagano 380-8553, Japan

*Corresponding author: wsugi@shinshu-u.ac.jp

\section{ABSTRACT}

The lateral size of individual graphene sheets is expected to impact the electrochemical properties of reduced graphite oxide nanosheets (rGOns). The size effect on the specific capacitance of rGOns was investigated by breaking down the size of rGOns using high-frequency ultrasonification. The specific capacitance of rGOns prepared by hydrogen reduction of GOns with an average equivalent diameter of $280 \mathrm{~nm}$ was $242 \mathrm{Fg}^{-1}$ in $0.5 \mathrm{M} \mathrm{H}_{2} \mathrm{SO}_{4}$ and $205 \mathrm{~F} \mathrm{~g}^{-1}$ in $0.5 \mathrm{M} \mathrm{Na}_{2} \mathrm{SO}_{4}$. The specific capacitance was $30 \%$ higher to that of larger-sized GOns with diameter of $920 \mathrm{~nm}$. The area normalized capacitance ranged between 70 to $138 \mu \mathrm{F} \mathrm{cm}^{-2}$, with larger-sized rGOns affording higher values. The cause of this size-effect is discussed based on the microstructure of the rGOns electrode as well as the edge/plane ratio.

(C) The Electrochemical Society of Japan, All rights reserved.

Keywords : Reduced Graphite Oxide Nanosheets, Graphene, Electrochemical Capacitor, Size-effect

\section{Introduction}

Graphene has attracted increased interest due to its high theoretical surface area, electron mobility and stability, ${ }^{1,2}$ in particular for electrochemical applications such as fuel cells and electrochemical capacitors. ${ }^{3}$ Although a number of methods have been developed for the preparation of graphene, ${ }^{4-10}$ the scalable and low cost approach using a sequential oxidation-exfoliation-reduction procedure has attracted most attention. The specific capacitance of graphene (reduced graphite oxide nanosheet) electrodes prepared by this approach ranges from 100 to $250 \mathrm{~F} \mathrm{~g}^{-1}$. The dispersed capacitance values is due at least in part to the difference in synthetic procedures, including the starting materials used, degree of exfoliation, degree of reduction, etc. The lateral size of reduced graphite oxide sheets is also expected to be one of the factors affecting the electrochemical properties. It has been reported that the specific capacitance of the edge plane of graphite is much higher than its basal plane; $\sim 50$ to $70 \mu \mathrm{F} \mathrm{cm}^{-2}$ for edge and $\sim 3 \mu \mathrm{F} \mathrm{cm}{ }^{-2}$ for basal plane. ${ }^{11}$ Biswas and Drzal showed that a thin film composed of large sized graphene nanosheets (lateral dimension of $15 \mu \mathrm{m}$ and thickness of 3-5 nm) and small-sized ones (average dimension of $500 \mathrm{~nm}$, thickness not given) gives specific capacitance of $80 \mathrm{~F} \mathrm{~g}^{-1}$, which is higher than that of the larged-size nanosheet alone of $36 \mathrm{~F} \mathrm{~g}^{-1} .{ }^{12}$ The small-sized nanosheets were prepared by mechanical milling of the large-size ones. ${ }^{12}$ We have also reported that reduced graphite oxide nanosheets derived from platelet carbon nanofibers (PCNFs) with average diameter of $150 \mathrm{~nm}$ gives approximately $60 \%$ higher specific capacitance compare to that derived from natural graphite with average size of $\sim 3 \mu \mathrm{m} .{ }^{13}$ Although rGOns prepared by this approach gives single-layered graphite oxide nanosheets with well defined size, the nanosheet size is determined by the nanofiber diameter, which is not easily controlled. Also, the synthetic method is not easily scalable due to the cost of the starting material and low yield. Thus, we were motivated to adopt a synthetic approach were a series of singlelayered graphite oxide nanosheets with different lateral size could be obtained in high yield and purity from a single starting material.

In this work, reduced graphite oxide nanosheets with different lateral size was prepared from the same graphite as starting material by different ultrasonic treatment, and the electrochemical capacitor behavior was studied in an attempt to clarify the relationship between the nanosheet size and capacitor performance. The lateral size of graphite oxide nanosheets was manipulated by controlled ultrasonic treatment of graphite oxide nanosheet colloids.

\section{Experimental}

Graphite oxide was prepared following the Hummers method ${ }^{14}$ using a graphite powder with average particle size of $4 \mu \mathrm{m}(\mathrm{Z}-5 \mathrm{~F}$, Ito Graphite Co., Ltd.) as the starting material. Graphite oxide was dispersed in ultrapure water $(>18 \mathrm{M} \Omega \mathrm{cm})$, then exfoliated to graphite oxide nanosheets (GOns) assisted by mild ultrasonic treatment with a common ultrasonic bath. Non-exfoliated GO was removed by centrifugation at $2000 \mathrm{rpm}$ for $30 \mathrm{~min}$, affording a homogeneous brownish colloid.

The as-prepared GOns colloid was subjected to high power ultrasonic treatment with frequency of $20 \mathrm{kHz}$ (VCX-750, Sonic \& Materials, Inc., $750 \mathrm{~W}$ ) for $30 \mathrm{~min}$ to breakdown the lateral size of GOns in the colloid. Further downsizing was conducted by ultrasonic treatment of the $20 \mathrm{kHz}$-treated colloid with higher frequency $(950 \mathrm{kHz}$, Mitsui Electric Co., Ltd., $300 \mathrm{~W})$ for 20 minutes.

The lateral size of individual GOns was evaluated using AFM (SPM-400, Seiko Instruments Inc.). Sub-monolayer of GOns was deposited on Si by dipping the substrate into the colloid for $10 \mathrm{~min}$, followed by mild washing with ultrapure water and drying under ambient conditions. The area $(A)$ and perimeter $(P)$ of individual GOns in the AFM images were measured, and the equivalent diameter $\left(D_{\mathrm{e}}\right)$ was calculated by:

$$
D_{\mathrm{e}}=\frac{4 \times A}{P}
$$

The size adjusted GOns colloids were dropped on a polished glassy carbon electrode, dried at $60^{\circ} \mathrm{C}$, and reduced at $200^{\circ} \mathrm{C}$ for 2 hours under $\mathrm{H}_{2} / \mathrm{Ar}(5 / 95)$ flow, or with $\mathrm{N}_{2} \mathrm{H}_{4} \cdot \mathrm{H}_{2} \mathrm{O}$ at $60^{\circ} \mathrm{C}$ for 24 hours. Cyclic voltammetry was conducted using a HZ-5000 system (Hokuto Denko Corp.) in $0.5 \mathrm{M} \mathrm{H}_{2} \mathrm{SO}_{4}$ or $0.5 \mathrm{M} \mathrm{Na}_{2} \mathrm{SO}_{4}$. 


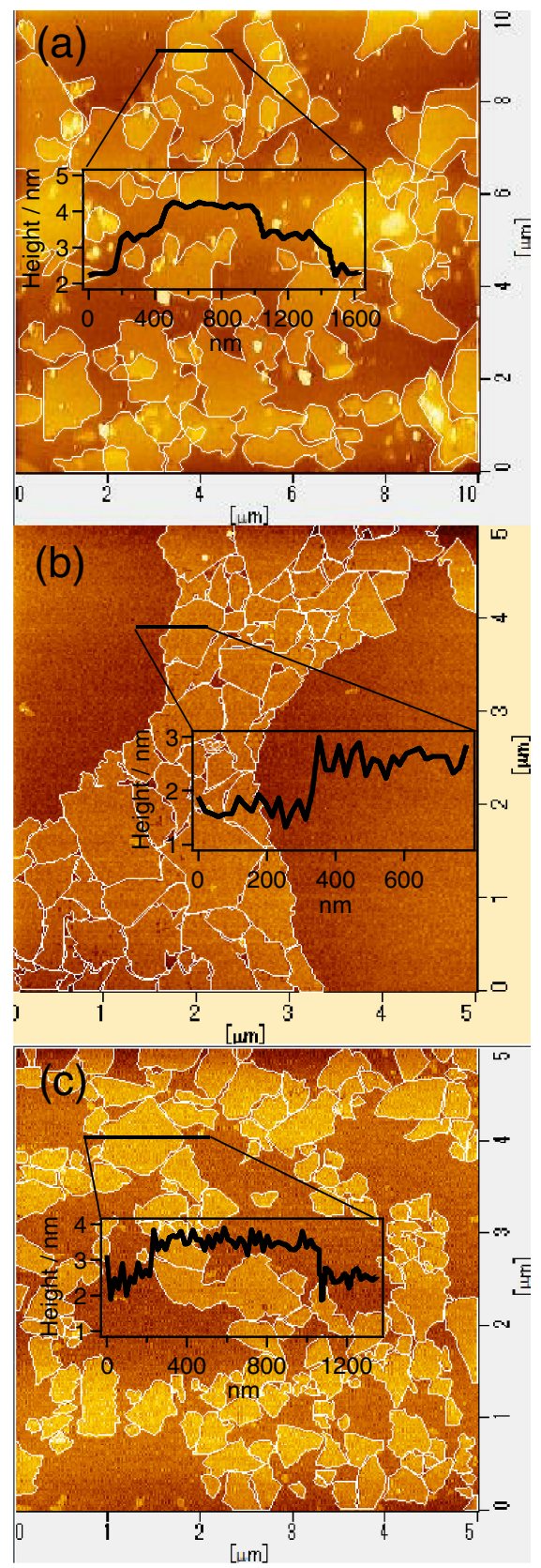

Figure 1. (Color online) AFM images of (a) GOns(920nm), (b) GOns(370nm), and (c) GOns(280nm).

X-ray diffraction (XRD) was conducted on RINT2550H/PC (Rigaku Corp.) with the colloids dropped on glass plate and dried at $60^{\circ} \mathrm{C}$. FE-SEM images were obtained using a Hitachi S-5000 system. X-ray photoelectron spectrometry was acquired with AXISULTRA DLD (Kratos Analytic Ltd.). The specific surface area of rGOns powder was measured by nitrogen adsorption at $77 \mathrm{~K}$ with Belsorp-18 (BEL Japan Inc.). Thermogravimetric analysis (TGA-50, Shimadzu Corp.) was conducted under $\mathrm{H}_{2} / \mathrm{Ar}(5 / 95)$ flow to estimate the oxygen content in GOns powder.

\section{Results and Discussion}

Figure 1 shows the AFM images of GOns with different ultrasonic treatment. All of the nanosheets had thickness of less than $1 \mathrm{~nm}$, indicating complete exfoliation of graphite oxide to individual GOns. GOns had negligible overlapping or folding, making it proper for evaluation of the nanosheet size. The calculated $D_{\mathrm{e}}$ were $921,373,277 \mathrm{~nm}$ for as-prepared, $20 \mathrm{kHz}$-treated, and
Table 1. The ratio of the different $\mathrm{C}$ species based on XPS for GOns (non-reduced) with different size.

\begin{tabular}{cccc}
\hline \multirow{2}{*}{ Sample } & \multicolumn{3}{c}{ Ratio of species (\%) } \\
\cline { 2 - 4 } & C-C & C-O & C (=O)-O \\
\hline GOns(920nm) & 53 & 34 & 13 \\
GOns(370nm) & 54 & 29 & 17 \\
GOns(280nm) & 54 & 26 & 20 \\
\hline
\end{tabular}

Table 2. $\mathrm{O} / \mathrm{C}$ ratio for $\mathrm{rGOns}(920 \mathrm{~nm}), \operatorname{rGOns}(370 \mathrm{~nm})$, and rGOns(280nm) reduced by $\mathrm{H}_{2}$ and $\mathrm{N}_{2} \mathrm{H}_{4}$.

\begin{tabular}{|c|c|c|}
\hline Reductant & Sample & $\mathrm{O} / \mathrm{C}$ \\
\hline \multirow{3}{*}{$\mathrm{H}_{2}$} & rGOns(920nm) & $15 / 85$ \\
\hline & rGOns(370nm) & $21 / 79$ \\
\hline & rGOns $(280 \mathrm{~nm})$ & $27 / 73$ \\
\hline \multirow{3}{*}{$\mathrm{N}_{2} \mathrm{H}_{4}$} & rGOns(920nm) & $10 / 90$ \\
\hline & rGOns(370nm) & $12 / 88$ \\
\hline & rGOns(280nm) & $13 / 87$ \\
\hline
\end{tabular}

$950 \mathrm{kHz}$-treated GOns, respectively. The samples will be denoted GOns(920nm), GOns(370nm), and GOns(280nm) hereafter.

Figures 2(a) and 2(b) show typical cyclic voltammograms in $0.5 \mathrm{M} \mathrm{H}_{2} \mathrm{SO}_{4}$ of GOns(920nm), GOns(370nm), and GOns(280nm) reduced by $\mathrm{H}_{2}$ or $\mathrm{N}_{2} \mathrm{H}_{4}$. The reduced samples will be denoted rGOns $(920 \mathrm{~nm})$, rGOns(370nm), and $\operatorname{rGOns}(280 \mathrm{~nm})$ hereafter. Redox peaks at $\sim 0.6 \mathrm{~V}$ were observed, suggesting the presence of oxygen-containing surface functionalities. For the $\mathrm{H}_{2}$-reduced series, the specific capacitance at $2 \mathrm{mV} \mathrm{s}^{-1}$ was 197,214 , and $242 \mathrm{~F} \mathrm{~g}^{-1}$ for rGOns(920nm), rGOns(370nm), and rGOns(280nm), respectively. It is noted that over $98 \%$ of the initial capacitance was maintained even after potential cycling tests of $\mathrm{rGOns}(280 \mathrm{~nm})$ in $0.5 \mathrm{M} \mathrm{H}_{2} \mathrm{SO}_{4}$ at $50 \mathrm{mV} \mathrm{s}^{-1}$ for 5000 cycles. The $\mathrm{N}_{2} \mathrm{H}_{4}$-reduced samples showed lower capacitance of 150,157 , and $192 \mathrm{~F} \mathrm{~g}^{-1}$ for rGOns(920nm), rGOns(370nm), and rGOns(280nm), respectively. In order to exclude the influence from redox-related capacitance, cyclic voltammetry was conducted in $0.5 \mathrm{M} \mathrm{Na}_{2} \mathrm{SO}_{4}$ for the $\mathrm{H}_{2}$-reduced series [Fig. 2(c)]. The specific capacitance for the $\mathrm{H}_{2}$-reduced samples were 185,193 , and $205 \mathrm{~F} \mathrm{~g}^{-1}$ for $\operatorname{rGOns}(920 \mathrm{~nm}), \operatorname{rGOns}(370 \mathrm{~nm})$, and $\mathrm{rGOns}(280 \mathrm{~nm})$, respectively. An increase in specific capacitance with the decrease of nanosheet size was observed even without contribution from pseudocapacitance (purely electrical-double layer charging).

The relative ratio of carbon with $\mathrm{C}-\mathrm{C}, \mathrm{C}-\mathrm{O}$, and $\mathrm{C}(=\mathrm{O})-\mathrm{O}$ bonding based on XPS (data not shown) for the samples before reduction are shown in Table 1 . As the sheet size decreases, a decrease in the relative ratio of $\mathrm{C}-\mathrm{O}$ bonds is observed, which is correlated with an increase in the ratio of $\mathrm{C}(=\mathrm{O})$-O bonds. The $\mathrm{O} / \mathrm{C}$ ratio for the samples reduced by both methods was calculated based on XPS and is summarized in Table 2. $\mathrm{H}_{2}$-reduced rGOns has a higher $\mathrm{O} / \mathrm{C}$ ratio compared to the $\mathrm{N}_{2} \mathrm{H}_{4}$-reduced samples, which explains the higher contribution from redox-related pseudocapacitance observed for the $\mathrm{H}_{2}$-reduced rGOns series (see Fig. 2). Another point worth noting is that more oxygen was found in samples with smaller sheet size. Again, this is in accord with the higher contribution from redox-related pseudo-capacitance observed for the rGOns with smaller nanosheet size.

Figure 3 shows the XRD patterns of the samples before and after reduction with $\mathrm{H}_{2}$ and $\mathrm{N}_{2} \mathrm{H}_{4}$. As the nanosheet size of GOns decreases, the inter-layer distance increases from 0.73 to $0.83 \mathrm{~nm}$. The peak is also weaker for smaller size GOns, suggesting that the smaller size GOns may be more loosely stacked and disordered than the larger size GOns. Reduced samples show a very weak and broad peak at $2 \theta \approx 25^{\circ}(d \approx 0.36 \mathrm{~nm})$, signifying that rGOns 

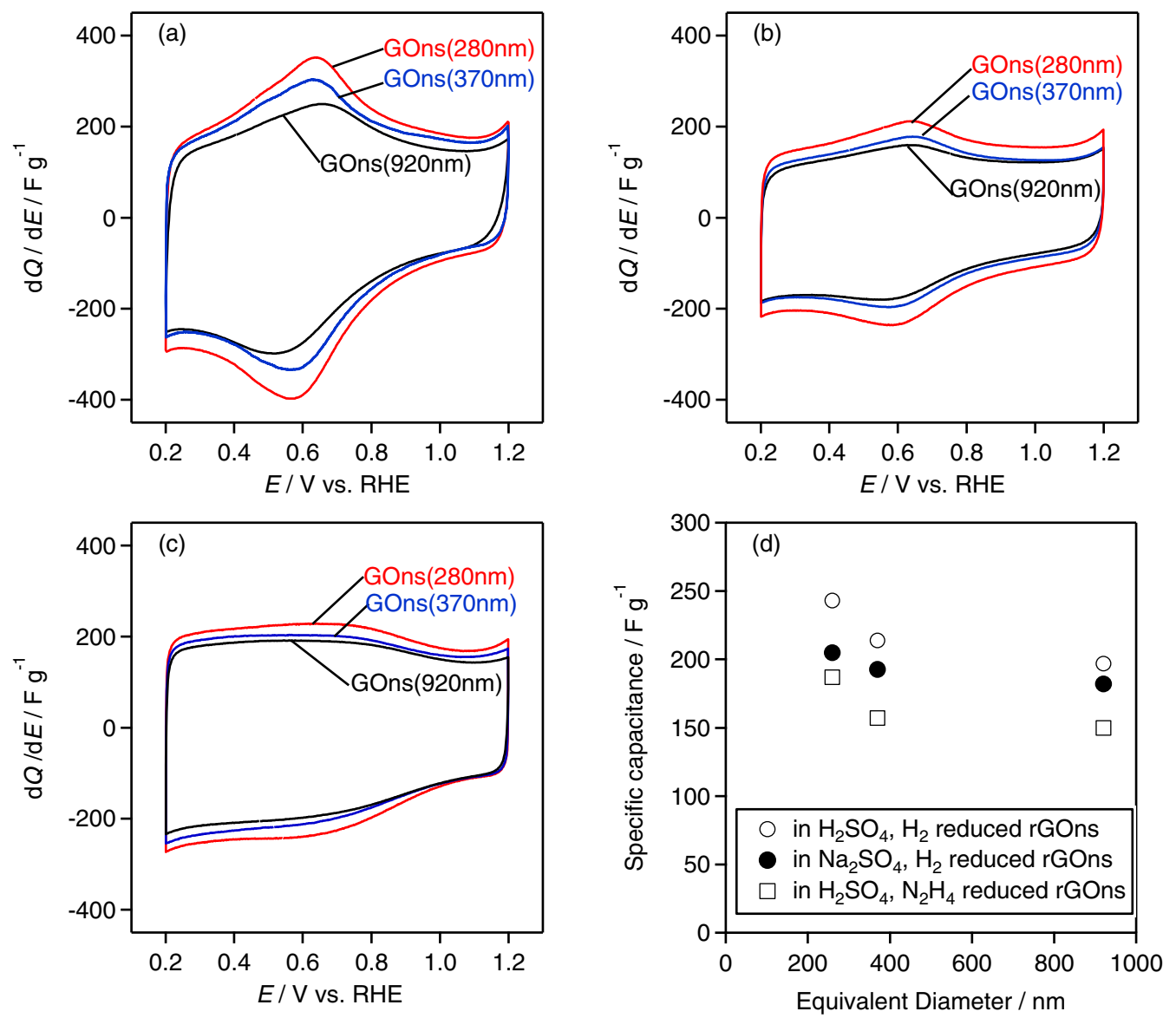

Figure 2. (Color online) Cyclic voltammograms of (a) $\mathrm{H}_{2}$ - and (b) $\mathrm{N}_{2} \mathrm{H}_{4}$-reduced samples in $0.5 \mathrm{M} \mathrm{H}_{2} \mathrm{SO}_{4}$, (c) $\mathrm{H}_{2}$-reduced samples in $0.5 \mathrm{M}$ $\mathrm{Na}_{2} \mathrm{SO}_{4}$, at $20 \mathrm{mV} \mathrm{s}^{-1}$. (d) The specific capacitance as a function of average equivalent diameter of rGOns taken from (a)-(c).

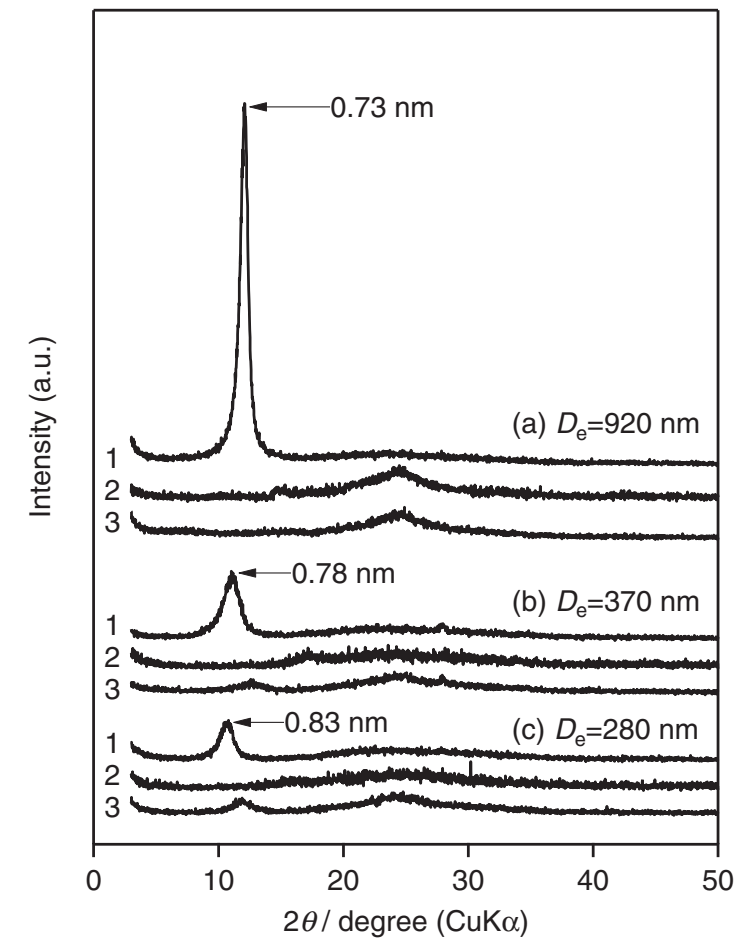

Figure 3. XRD patterns for (1) non-reduced, (2) $\mathrm{H}_{2}$-reduced, and (3) $\mathrm{N}_{2} \mathrm{H}_{4}$-reduced samples of GOns with $D_{\mathrm{e}}=$ (a) $920 \mathrm{~nm}$, (b) 370 $\mathrm{nm}$, and (c) $280 \mathrm{~nm}$.

is more disordered and heterogeneous than GOns. The peak at $d \approx 0.36 \mathrm{~nm}$ in rGOns is slightly weaker for rGOns with smaller size. This may suggest that rGOns(370nm) and rGOns(280nm) has a more disordered lamellar structure compared to $\mathrm{rGOns}(920 \mathrm{~nm})$. In fact, SEM images of the $\mathrm{H}_{2}$ reduced samples (Fig. 4) seems to show rGOns $(920 \mathrm{~nm})$ with a smoother surface morphology than rGOns $(370 \mathrm{~nm})$ and rGOns(280nm).

In order to define the effect of pore structure, adsorption/ desorption isotherms were measured for the $\mathrm{H}_{2}$-reduced samples (Fig. 5). The BET surface area was 143,247 , and $293 \mathrm{~m}^{2} \mathrm{~g}^{-1}$ for rGOns(920nm), rGOns(370nm), and rGOns(280nm), respectively. rGOns $(920 \mathrm{~nm})$ has a sharp pore size distribution centered at $r_{\mathrm{p}} \sim 1.7 \mathrm{~nm}$, or diameter of $3.4 \mathrm{~nm}$. The main peak in the pore size distribution is shifted to slightly larger region $\left(r_{\mathrm{p}} \sim 1.9 \mathrm{~nm}\right)$ for rGOns(370nm) and rGOns(280nm). While most of the pores for $\operatorname{rGOns}(920 \mathrm{~nm})$ are below $r_{\mathrm{p}} \sim 2.5 \mathrm{~nm}, \operatorname{rGOns}(370 \mathrm{~nm})$ and rGOns $(280 \mathrm{~nm})$ have medium to large-size mesopores. The results agree with the XRD and SEM analysis that showed more disorder for the smaller-sized rGOns.

Based on the above findings, the reason for the increase in specific capacitance of rGOns with decreasing nanosheet size is discussed. It was reported that the edge of graphite oxide is mainly $\mathrm{COOH}$, while $\mathrm{COH}$ and $\mathrm{C}-\mathrm{O}-\mathrm{C}$ is present on the basal plane. ${ }^{15}$ When GOns is broken down by ultrasonic treatment, a large number of C-dangling bonds should be created on the newly generated edges. These highly active dangling bonds will be easily oxidized to $\mathrm{COOH}$ on the edge. Thus, rGOns with smaller size should have more edge $\mathrm{C}=\mathrm{O}$ and less basal $\mathrm{C}-\mathrm{O}$ bonding compared to larger ones. The overall content of surface functional groups will be higher for smaller rGOns, leading to higher pseudo-capacitance. These surface functional groups will contribute to pseudo-capacitance in the case of acidic electrolyte.

Table 3 summarizes the specific capacitance per unit surface area of $\mathrm{H}_{2}$ reduced samples in $\mathrm{H}_{2} \mathrm{SO}_{4}$ and $\mathrm{Na}_{2} \mathrm{SO}_{4}$. The area-specific capacitance is $\sim 100 \mu \mathrm{F} \mathrm{cm}^{-2}$, which is much higher than the often 

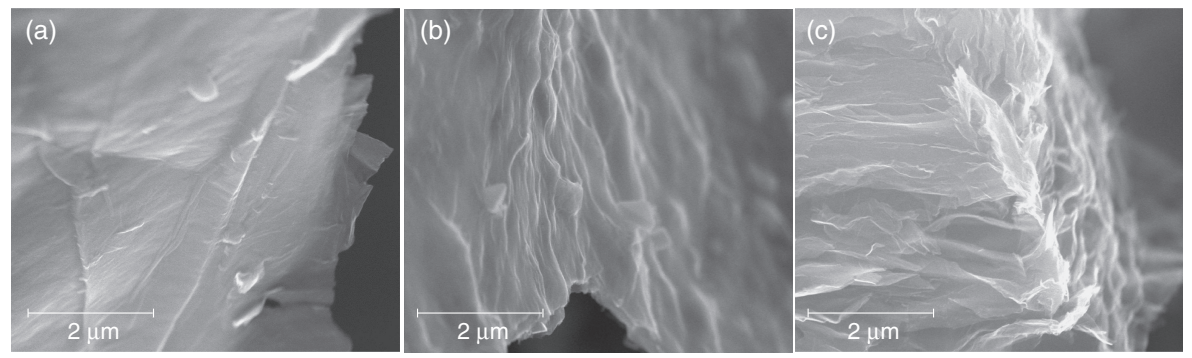

Figure 4. FE-SEM images of $\mathrm{H}_{2}$-reduced (a) rGOns(920nm), (b) rGOns(370nm), and (c) rGOns(280nm).
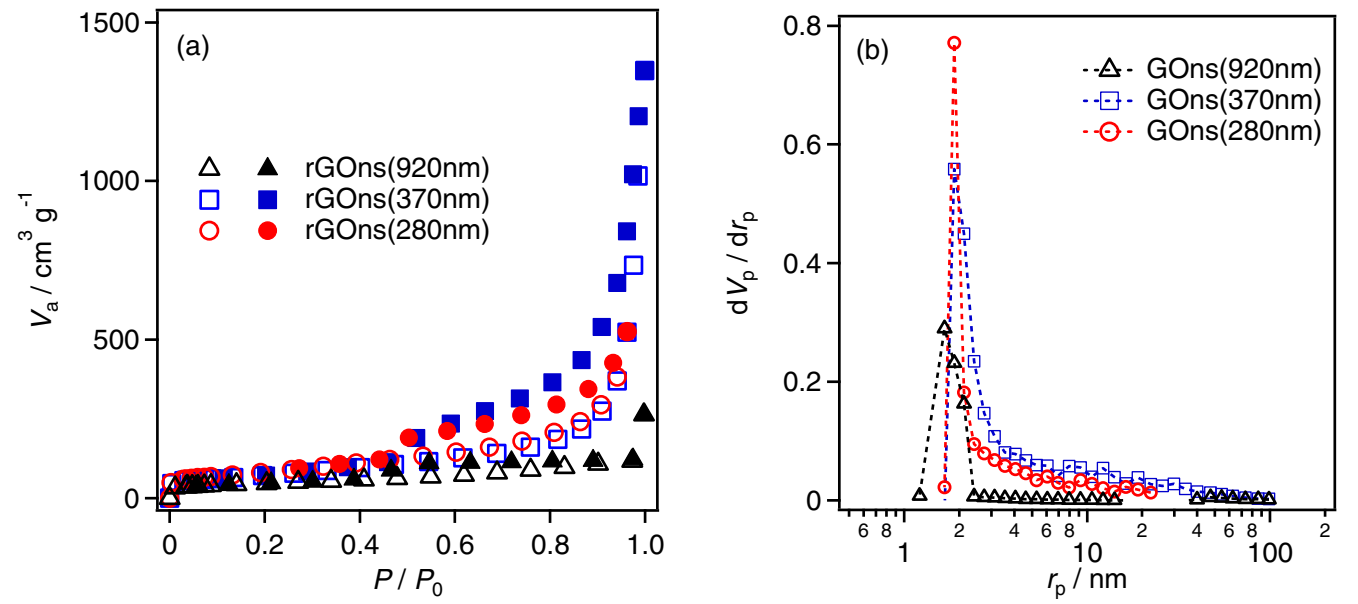

Figure 5. (Color online) (a) Adsorption (open plots)/desorption (filled plots) isotherms and (b) pore size distribution curves (BJH plot) for $\mathrm{H}_{2}$-reduced rGOns with $D_{\mathrm{e}}=920,370$, and $280 \mathrm{~nm}$.

Table 3. Area-specific capacitance of $\mathrm{H}_{2}$-reduced sample in different electrolytes.

\begin{tabular}{ccc}
\hline \multirow{2}{*}{ Sample } & \multicolumn{2}{c}{ Specific capacitance $/ \mu \mathrm{F} \mathrm{cm}^{-2}$} \\
\cline { 2 - 3 } & $0.5 \mathrm{M} \mathrm{H}_{2} \mathrm{SO}_{4}$ & $0.5 \mathrm{M} \mathrm{Na}_{2} \mathrm{SO}_{4}$ \\
\hline rGOns(920nm) & 138 & 129 \\
$\mathrm{rGOns}(370 \mathrm{~nm})$ & 87 & 78 \\
$\mathrm{rGOns}(280 \mathrm{~nm})$ & 83 & 70 \\
\hline
\end{tabular}

observed typical value of $\sim 20 \mu \mathrm{F} \mathrm{cm}^{-2}$. $^{16,17}$ This is tentatively attributed to the narrow pore size distribution of rGOns. In fact, the area-specific capacitance decreases with decreasing nanosheet size, which is in agreement with the wider pore size distribution for $\operatorname{rGOns}(370 \mathrm{~nm})$ and $\mathrm{rGOns}(280 \mathrm{~nm})$. Although the gravimetric capacitance increases as the nanosheet size decreases, the areaspecific capacitance is smaller for smaller-sized nanosheets in both $\mathrm{H}_{2} \mathrm{SO}_{4}$ and $\mathrm{Na}_{2} \mathrm{SO}_{4}$ electrolytes. This seems at first glance to contradict with the assumption that the edge sites have higher areaspecific capacitance than the planes. However, as mentioned above, the porosity must also be taken into consideration. In order to conclude that the edges have higher capacitance per unit surface area, material with the same porosity must be synthesized.

\section{Conclusion}

The specific capacitance of graphite oxide nanosheets reduced by hydrogen or hydrazine was successfully enhanced by reducing the lateral size of the nanosheets before reduction with high frequency ultrasonic treatment. The increase in capacitance with the decrease in lateral size is attributed to at least two causes, the higher specific surface area of reduced graphite oxide nanosheets with smaller nanosheet size, and the edge-induced increase of functional groups. A high specific capacitance of $240 \mathrm{~F} \mathrm{~g}^{-1}$ in $\mathrm{H}_{2} \mathrm{SO}_{4}$ and $205 \mathrm{~F} \mathrm{~g}^{-1}$ in
$\mathrm{Na}_{2} \mathrm{SO}_{4}$ at $2 \mathrm{mV} \mathrm{s}^{-1}$ was achieved for $\mathrm{H}_{2}$-reduced graphite oxide nanosheets with an equivalent diameter of $280 \mathrm{~nm}$. The unusually high capacitance per unit surface area of $\sim 100 \mu \mathrm{F} \mathrm{cm}^{-2}$ is expected to lead to a higher volumetric capacitance than conventional activated carbons.

\section{Acknowledgments}

This work was supported in part by Global COE program and CREST of the Japan Science and Technology Agency (JST).

\section{References}

1. A. K. Geim and K. S. Novoselov, Nat. Mater, 6, 183 (2007).

2. K. I. Bolotin, K. J. Sikes, Z. Jiang, M. Klima, G. Fudenberg, J. Hone, P. Kim, and H. L. Stormer, Solid State Commun., 146, 351 (2008).

3. D. A. Brownson, D. K. Kampouris, and C. E. Banks, J. Power Sources, 196, 4873 (2011).

4. K. S. Novoselov, A. K. Geim, S. V. Morozov, D. Jiang, Y. Zhang, S. V. Dubonos, I. V. Grigorieva, and A. A. Firsov, Science, 306, 666 (2004).

5. X. Li, W. Cai, J. An, S. Kim, J. Nah, D. Yang, R. Piner, A. Velamakanni, I. Jung, E. Tutuc, S. K. Banerjee, L. Colombo, and R. S. Ruoff, Science, 324, 1312 (2009).

6. S. Bae, H. Kim, Y. Lee, X. Xu, J. Park, Y. Zheng, J. Balakrishnan, T. Lei, H. R. Kim, Y. I. Song, Y. J. Kim, K. S. Kim, B. Ozyilmaz, J. H. Ahn, B. H. Hong, and S. Iijima, Nat. Nanotechnol., 5, 574 (2010).

7. M. D. Stoller, S. Park, Y. Zhu, J. An, and R. S. Ruoff, Nano Lett., 8, 3498 (2008).

8. Y. Zhu, S. Murali, M. D. Stoller, A. Velamakanni, R. D. Piner, and R. S. Ruoff, Carbon, 48, 2118 (2010).

9. Z. Lin, Y. Liu, Y. Yao, O. J. Hildreth, Z. Li, K. Moon, and C. Wong, J. Phys. Chem. C, 115, 7120 (2011).

10. Y. Wang, Z. Shi, Y. Huang, Y. Ma, C. Wang, M. Chen, and Y. Chen, J. Phys. Chem. C, 113, 13103 (2009).

11. J. Randin and E. Yeager, J. Electrochem. Soc., 118, 711 (1971).

12. S. Biswas and L. T. Drzal, ACS Appl. Mater. Interfaces, 2, 2293 (2010).

13. J. Sato, Y. Takasu, K. Fukuda, and W. Sugimoto, Chem. Lett., 40, 44 (2011).

14. W. S. Hummers and R. E. Offeman, J. Am. Chem. Soc., 80, 1339 (1958).

15. A. Lerf, H. He, M. Forster, and J. Klinowski, J. Phys. Chem. B, 102, 4477 (1998).

16. B. E. Conway, Electrochemical Supercapacitor: Scientific Fundamentals and Technological Applications, Kluwer (1999).

17. J. Xia, F. Chen, J. Li, and N. Tao, Nat. Nanotechnol., 4, 505 (2009). 